\title{
Photoelectric professional students in common universities cultivate way to explore under the background of professional certification
}

Yan-jun Sun, Li Wang, Yan-bing Leng

Yan-jun Sun, Li Wang, Yan-bing Leng, "Photoelectric professional students in common universities cultivate way to explore under the background of professional certification," Proc. SPIE 10452, 14th Conference on Education and Training in Optics and Photonics: ETOP 2017, 104523V (16 August 2017); doi: 10.1117/12.2264601

SPIE Event: 14th Conference on Education and Training in Optics and Photonics, ETOP 2017, 2017, Hangzhou, China 


\title{
Photoelectric professional students in common universities cultivate way to explore under the background of professional certification
}

\author{
Sun yan-jun, Wang li, Leng yan-bing \\ The School of photo-electronic engineering,Changchun University of Science and Technology./ \\ Changchun 13002 China
}

\begin{abstract}
In view of the engineering education professional certification of specialty construction and the specific requirements of the training system, combining with our school optoelectronic information science and engineering characteristics, analysis of the optoelectronic information science and engineering in our school problems and challenges, to locate the specific professional training objectives. From the service oriented industry demand for talent ability, at the same time, according to the ministry of education professional norms of the development of the photoelectric teaching steering committee, and the professional development and the characteristics of target, to build a set to conform to the goal of cultivating the professional curriculum system. At the same time set up a from fundamental to professional practice teaching system, covers the course experiment, course design, case teaching, comprehensive training, such as graduation design practice. Which implements a whole ability training from the practice of foundation to high-end chain, embodies the training goal emphasize "outstanding practical skills, quality education is distinct culture characteristic. By further speed up the professional construction, professional certification standards to standardize our training process, improved the level of professional training, and improve the comprehensive quality of the graduates and talent of social competitiveness, fostered more professional talents for the country.
\end{abstract}

Keywords: Professional certification, optoelectronic information science and engineering, training goal, practice teaching system, graduation design practice

\section{INTRODUCTION}

Engineering education professional certification are recognized is the present international engineering education quality guarantee system, and also is the important foundation of realization of engineering education international mutual recognition. This is considered to a recognition of talents cultivation at colleges and universities, also is our country physical talent here towards the international market. The significance of this work is to draw lessons from international engineering education professional certification of mature experience, combined with the concrete practice of professional construction in our country, promote the teaching reform of engineering education, build and perfect, suitable for professional education with Chinese characteristics, reflecting the industry demand, and promote the professional reform and actual construction engineering education professional certification system. Engineering education professional certification in our country started a little slower, began in 2006, after years of efforts, there are more colleges and universities have many professional certified. These successful experiences show that professional certification to the result from the process, to improve the quality of teaching played a very important role in promoting. The authentication process is the construction of professional learning, keep improving, continuous innovation of the process of ascension. Professional certification can make further clear training objectives of colleges and universities, further attention to professional training and social needs of the community, to improve the level of student employment, the purpose of improving students' comprehensive ability.

Our school of optoelectronic information science and engineering (work) a long history. Its predecessor was approved in 1958 professional optical instruments, optical instruments in 1974 professional is divided into two major (i.e., optical instruments and optical process), in 1993 two major merger and photoelectric instrument for optical technology professional, in 1998 changed its name to the measurement and control technology and instrument specialty, is divided into 2003 photoelectric information engineering and two of measure and control technology and instrument specialty,

14th Conference on Education and Training in Optics and Photonics: ETOP 2017, edited by Xu Liu,

Xi-Cheng Zhang, Proc. of SPIE Vol. 10452, 104523V · @ 2017 ICO, IEEE, OSA, SPIE

CCC code: $0277-786 \mathrm{X} / 17 / \$ 18 \cdot$ doi: $10.1117 / 12.2264601$ 
photoelectric information engineering in 2013 changed its name to the photoelectric information science and engineering (engineering).As a local key universities, after decades of development, in such aspects as specialty construction and talent cultivation has made gratifying achievements, for the country by churning out generations of excellent optical professionals, for the optical industry and local economic construction in China has made a positive contribution. In recent years, in the face of international competition and the grim situation of employment, how to do the professional characteristics of our school, to cultivate professional talents with social competitive advantage, is we continuously explore issues. Engineering education professional certification pointed out the direction for our professional construction. Control standards, we need to perfect the current training scheme and innovation.

\section{SPECIALIZED TRAINING GOAL ORIENTATION}

In optoelectronic information science and engineering personnel training system, training target is a common problem is too general, because the training objectives and the needs of society without a good starting point, the talent training and social needs disjointed situation. This time, in the study of professional training target, we carefully grasp the guiding ideology of professional certification, in accordance with the requirements for certification standards of "professional Settings to adapt to the countries and regions, industry the need of economic development, adapt to the needs of scientific and technological progress and social development, in line with the school own conditions and development planning, there is a clear service oriented and talent demand", from three aspects, has carried on the comprehensive social research. Firstly, investigating the high level of colleges and universities, especially already through the authentication, and is ready for a certification of the school. Study they do professional idea, learn their advanced teaching thought and teaching method, draw lessons from their advanced experience. Secondly, widely research social demand, the domestic optical industry investigation and study, understand their requirements to personnel qualities. Third, understand the employment of graduates from our school, analyze their levels of employment. At the same time, summarizes the advantages of running school. In nearly seventy years of development, our school as one of the oldest schools, optical industry for the optical industry and equipment manufacturing industry in our country has trained a large number of excellent talents, in the optical field and optical technology and equipment industry in our country enjoys a high reputation, as well as trained a large number of outstanding talents for the local economic development of jilin province. Have a clear guiding ideology, according to the survey results, we have established a professional training objectives. That faces the field of optics and optical information demand and local economic development of jilin province, optical design and processing technology of culture has a solid theoretical foundation, complete engineering technical training, has the innovation spirit and practice ability of senior engineering and technical personnel of information. To highlight and strengthen the "features in the industry, professional basis, practical skills, heavy quality education in" talent training characteristics. Adhere to cultivating students' noble personality and sound psychology as the prerequisite, on the basis of cultivating excellent quality and comprehensive quality, to cultivate the innovation spirit and practice ability as the key point, put our photoelectric characteristic advantages and combined closely with the local economy in jilin province, to meet the needs of the local economy and society, in the same distinctive professional education.

\section{COURSE TEACHING SYSTEM CONSTRUCTION}

The emphasis of professional certification system is training objectives to cultivate one-to-one correspondence. Training target is the core of the professional construction, around the core, must adopt scientific and effective implementation, to ensure the realization of training objectives. Training scheme research including teaching system, that is, teaching system, practical teaching system construction, etc., in addition, the construction of teachers team construction, teaching material, teaching means, teaching quality supervision system reform, etc., are to realize the goal of cultivating the professional guarantee. This article only teaching system in the process of training scheme, the results of other issues, on the other, in this paper. Professional certification standard requirements for the curriculum training scheme "in the service of professional training objectives, meet the requirement forecast ability of graduates, curriculum design in business or industry experts". according to the request, when we adjust professional training scheme, based on training target, from a service oriented industry demand for talent ability, at the same time, according to the ministry of education professional norms of the development of the photoelectric teaching steering committee, and the professional development and the characteristics of target, to build a set to conform to the goal of cultivating the professional curriculum system. Follow the guiding ideology, based on the research results on this topic, we have formulated a set of photoelectric information science and engineering (work) training scheme of course system. This scheme of course 
system, in accordance with the general education courses, subject courses and professional characteristics of tertiary course platform to build, as shown in table 1.

Table 1. Curriculum system structure

\begin{tabular}{|c|c|c|c|c|}
\hline \multirow{5}{*}{$\begin{array}{l}\text { curricul } \\
\text { um } \\
\text { system }\end{array}$} & $\begin{array}{l}\text { The } \\
\text { primary } \\
\text { platform }\end{array}$ & \multicolumn{2}{|c|}{ Public basic course platform } & $\begin{array}{l}\text { Political theory, policy situation, mathematics, English, sports } \\
\text { and other required content as well as the humanities and social } \\
\text { science, natural science, engineering technology, such as } \\
\text { literature and art study content }\end{array}$ \\
\hline & $\begin{array}{l}\text { The } \\
\text { secondar } \\
\text { y } \\
\text { platform }\end{array}$ & \multicolumn{2}{|c|}{ Professional basic course platform } & $\begin{array}{l}\text { complex variable function and integral transform, engineering } \\
\text { drawing and CAD, electronic technology, engineering } \\
\text { mechanics, mechanical principle, physical optics, applied optics, } \\
\text { instrument parts design and CAD, tolerance and error theory, the } \\
\text { principle and application of single-chip microcomputer, sensor } \\
\text { and testing technology, instrument manufacturing technology, the } \\
\text { principle and application of laser, optical measurement, modern } \\
\text { optical testing technology, photoelectric detection technology, the } \\
\text { Fourier optics, optical design, optical technology and other } \\
\text { professional backbone course }\end{array}$ \\
\hline & \multirow{3}{*}{$\begin{array}{l}\text { three- } \\
\text { level } \\
\text { platform }\end{array}$} & \multirow{3}{*}{$\begin{array}{l}\text { Profession } \\
\text { al } \\
\text { specialty } \\
\text { course } \\
\text { platform }\end{array}$} & Optical design direction & $\begin{array}{l}\text { Modern optical system design, photoelectric material, light } \\
\text { machine structure design, etc }\end{array}$ \\
\hline & & & $\begin{array}{l}\text { Optical manufacturing } \\
\text { direction }\end{array}$ & $\begin{array}{l}\text { Modern optical micro-nano manufacturing technology, } \\
\text { manufacturing technology, optical, thin film optics and } \\
\text { technology, etc }\end{array}$ \\
\hline & & & $\begin{array}{l}\text { The direction of optical } \\
\text { information and optical } \\
\text { communications }\end{array}$ & $\begin{array}{l}\text { Optical communication technology, photoelectron technology } \\
\text { and devices, optical information processing technology, } \\
\text { spectroscopy, etc }\end{array}$ \\
\hline
\end{tabular}

The first platform for public basic course, mainly to the cultivation of students' comprehensive quality. Courses include political theory, policy situation, mathematics, English, sports and other required content as well as the humanities and social science, natural science, engineering technology, such as literature and art study content. Second platform for professional basic course, on the cultivation of the students' professional foundation quality optical engineering direction, on the basis of optoelectronic information science and engineering (work) the knowledge system, set up the complex variable function and integral transform, engineering drawing and $\mathrm{CAD}$, electronic technology, engineering mechanics, mechanical principle, physical optics, applied optics, instrument parts design and $\mathrm{CAD}$, tolerance and error theory, the principle and application of single-chip microcomputer, sensor and testing technology, instrument manufacturing technology, the principle and application of laser, optical measurement, modern optical testing technology, photoelectric detection technology, the Fourier optics, optical design, optical technology and other professional backbone course. The third platform characteristic of professional course, fully embodies the target of profession fostering, reflects the characteristics of professional training, strengthen the professional application ability of students. According to the field of photoelectric and jilin province the local economic development urgently needs new knowledge system, set up the modern optical system design, photoelectric material, light machine structure design, modern optical micro-nano manufacturing technology, manufacturing technology, optical, thin film optics and technology, optical communication technology, photoelectron technology and devices, optical information processing technology, such as spectroscopy characteristic curriculum.

In order to make the students master the latest technology in the field of photoelectric, after to be going to work as soon as possible to adapt to the technical requirements for application development courses is also equipped with some cutting-edge technology. Along with the continuous renewal of application technology, adjust this part of the course content.

\section{PRACTICAL TEACHING SYSTEM CONSTRUCTION}

Professional certification standards "for the students with the chance to participate in the engineering practice, so that the students in independent, hands-on, comprehensive, experiment and creative ability, etc, to get some exercise". In training goal, will also be active innovation spirit and practice ability as a training focus. Around this point, in the training plan to build a set from the fundamental to the professional practice teaching system, covers the course experiment, course 
design, case teaching, comprehensive training, graduation design, such as practice, and appropriately increase the period of practice teaching. Which implements a whole ability training from the practice of foundation to high-end chain, embodies the training goal emphasize "outstanding practical skills, quality education is distinct culture characteristic. Practice teaching carried out in accordance with the five stages set, as shown in table 2.

Table 2. The practice teaching link

\begin{tabular}{|l|l|l|l|}
\hline \multirow{4}{*}{$\begin{array}{l}\text { The } \\
\text { practice } \\
\text { teaching } \\
\text { link }\end{array}$} & The first stage & Experiment courses & $\begin{array}{l}\text { Physical optics experiment, comprehensive experiment applied } \\
\text { optics, photoelectric information comprehensive experiment, etc }\end{array}$ \\
\cline { 2 - 4 } & The third stage & Examples of teaching & $\begin{array}{l}\text { Comptical design comprehensive course design, software engineering } \\
\text { curriculum design curriculum design, instrument parts, etc } \\
\text { or the practice of the whole project development process }\end{array}$ \\
\cline { 2 - 4 } & The fourth stage & $\begin{array}{l}\text { Comprehensive } \\
\text { training }\end{array}$ & $\begin{array}{l}\text { To practice base, teaching by experienced industry experts, of the } \\
\text { actual project development training for two weeks }\end{array}$ \\
\cline { 2 - 4 } & The fifth stage & Graduation design & $\begin{array}{l}\text { To complete a relatively independent design and development } \\
\text { projects, is a test of the students' comprehensive knowledge, ability }\end{array}$ \\
\cline { 2 - 4 } & \multicolumn{2}{|l|}{ Innovation practice } & $\begin{array}{l}\text { Off-campus practice base, all kinds of competition, or to participate } \\
\text { in the activities of teachers' scientific research, etc }\end{array}$ \\
\hline
\end{tabular}

The first phase of experiment courses, including physical optics experiment, comprehensive experiment applied optics, photoelectric information comprehensive experiment, etc. After complete theoretical knowledge teaching, the students use $1 \sim 2$ weeks, and experimental verification, the content of the course of knowledge so as to improve the understanding of knowledge. The second phase for curriculum design, including optical design comprehensive course design, software engineering curriculum design curriculum design, instrument parts, etc. The link of each course design will improve the student to utilize the knowledge solution actual problem ability. The third stage for instance teaching, this link to complete a large application project in the field of reverse analysis or the practice of the whole project development process. The fourth stage for the comprehensive training, the link to practice base, taught by experienced industry experts, for two weeks of actual project development practice, in order to improve students' professional knowledge and understanding in the field of application. Stage 5 for graduation design, graduation design completed a relatively independent design and development projects, is a test of the students' comprehensive knowledge, ability, and improve students' innovative and practical ability of comprehensive practice at a time. The comprehensive practice will use for 16 weeks, the students under the guidance of teachers to complete a project design for application development, at the same time to arrange some students directly in the enterprise to complete the graduation design. Contact with the society, besides, in order to increase the students the opportunity to participate in industry production, we combined with the enterprise set up a number of off-campus practice bases, regularly send students to the practice base for practice. To have the ability of students can also participate in various competitions, or participate in teachers' scientific research activities. Such a complete chain of practice ability, ensure that every student can obtain the comprehensive ability to exercise, to lay a solid foundation for the students to the society.

\section{CONCLUSION}

Professional certification for professional construction and development has the very good role in promoting. More meaningful, we by the concept of certification and standard as the guiding ideology, training objectives and training scheme as the breakthrough point, the training mode of optoelectronic information science and engineering has carried on the preliminary reform and practice, has achieved initial success. But this is just the start of our professional construction process, in the future, we will also continue to work hard, to conduct the thorough research to the other problems of the construction of the professional. Although we also far from the requirement of professional certification, but we will continue efforts. Certification as an opportunity, our goal is to further speed up the construction of professional, with professional certification standards to standardize our training process, improve the level of our professional training, so as to improve the comprehensive quality of graduates, improving the social competitive power, to cultivate more excellent professional talents for the country. 


\section{REFERENCES}

[1] Wu qi-di, steadily push forward the professional certification \% engineering education international competitiveness [J]. China's higher education, 241-248 (2009).

[2] Luo zheng-xiang, engineering education professional certification and its influence on the practice teaching of colleges and universities [J]. Journal of laboratory research and exploration, 141-143(2008).

[3] Cai Jin-chao Xia Yu-yan, current situation, problems and countermeasures of Chinese higher engineering education research based on the perspective of international higher engineering education professional certification [J]. Journal of Inner Mongolia normal university (education sciences) , 24-28 (2010).

[4] Zhang jian-cheng, Zhao Lin-hui, The combination between production to promote personnel training new model [J]. Journal of education and profession , 322-325 (2012).

[5] Jia wei-ping. Under the background of engineering education accreditation applied mechanical talents construction of engineering ability training system [J]. Journal of experimental technology and management , 96-101 (2015). 